\title{
The University of the Philippines College of Medicine: Pioneer in Medical Education Innovations in the Philippines
}

\author{
Coralie Therese C. Dioquino-Dimacali \\ College of Medicine, University of the Philippines Manila
}

\begin{abstract}
Introduction
The University of the Philippines College of Medicine (UPCM) has been at the forefront of innovations in medical education. Established in 1905 as the Philippine Medical School by virtue of Act 1415 of the second Philippine Commission, it was renamed the University of the Philippines College of Medicine and Surgery in 1910 and later on shortened to its existing name, the University of the Philippines College of Medicine, in 1923. Because it was the result of Filipino-American cooperative effort, its initial medical curriculum followed standard American curricula which was Flexnerian in nature, and emphasized the scientific basis for the practice of medicine with a strict distinction between basic sciences usually taken in the first two years and clinical sciences taken in the last two years. This type of curriculum is usually referred to as the traditional medical curriculum.

Major curricular innovations were done in the 1970's with the introduction of community orientation and integration. In 1969, the Comprehensive Community Health Program (CCHP) was launched in the UPCM as a pioneering attempt by the academe to address community health needs through more appropriate community health technologies. Medical students were required to rotate in CCHP sites during their clinical clerkship and internship years under the supervision of CCHP faculty. This paved the way for the development of community orientation in the college. In 1982, the Board of Regents of the University of the Philippines approved the implementation of an Integrated Arts and Medicine (INTARMED) curriculum that shortened medical education by two years and provided for the teaching of humanities throughout the seven years. These efforts were done well ahead of the international clamor for innovative curricula during the 1st World Summit in Medical Education in 1988. Evaluations of the INTARMED program implementation in 1994 revealed that courses were still heavily discipline-based and teacher-directed. On April
\end{abstract}

Corresponding author:

Coralie Therese D. Dimacali, MD

College of Medicine

University of the Philippines Manila

547 Pedro Gil Street, Ermita, Manila 1000 Philippines

Telephone: +632 5361392

Email: cddimacali@up.edu.ph
21, 2003, the UP-Manila University Council approved the full implementation of the integrated medical curriculum which used organ systems as foci for learning. Some of the additional features of this curriculum included: (1) the addition of learning objectives that develop psychomotor skills and attitudes, (2) focus on the must know, (3) competency-based and outcome-based curricular design, (4) increase in the use of small group discussions vs. lectures, (5) clinical teaching that is complaint-based rather than diseasebased, and community-oriented rather than hospital-based, and (6) use of student assessments that are more integrated, emphasize critical thinking and problem-solving and are criterion-referenced rather than norm-referenced. The organ system integrated (OSI) curriculum was implemented in Academic Year 2004-2005 starting with Learning Unit III (first year medicine proper). Since 2009, graduates of this program have shown comparable, if not better, performance in the physician licensure examinations given by the Professional Regulation Commission as compared to graduates of the traditional medical curriculum. Their interests have also diversified. While the clinician track was most often the only choice after graduation from the traditional curriculum, the OSI curriculum has produced graduates who now go into health policy, research, academe and community practice.

The UPCM has been granted Level IV Re-Accredited status for its Basic Medical Education program effective April 24, 2015 to November 2019 by the Federation of Accrediting Agencies of the Philippines following a reaccreditation visit by the Philippine Accrediting Association of Schools, Colleges and Universities (PAASCU). The UPCM has also been recognized as a Commission on Higher Education (CHED) Center of Excellence for Medicine effective December 2015 based on CHED Memorandum Order No. 38, Series of 2015.

\section{The UPCM Beginnings}

The initial medical curriculum of the UPCM followed standard American curricula except for the inclusion of tropical medicine to emphasize the study of tropical diseases then rampant in the Philippines at that time. This Flexnerian curriculum emphasized the scientific basis for the practice of medicine and was a 5-year course consisting of two years of basic sciences, two years of clinical sciences and one year of clinical clerkship. The curriculum was discipline-based and 
teacher-centered, and the classroom was the main venue for instruction. ${ }^{1}$ As stipulated by Act 1632 of the second Philippine Commission, initial graduates were given the right to practice medicine and surgery in the Philippines without having to take the required Medical Board Examination. ${ }^{2}$ To augment the need for government physicians, entrants to the school in 1915 were required to sign a contract that would commit themselves to government service for at least two years after graduation in exchange for a waiver of tuition fees for the 5-year medical course. However, in 1920, the contracts were forgotten and the graduates were required to take the Medical Board Examination upon repeal of Act 1632 in 1921. Dr. Narciso Cordero narrates that as the curriculum evolved, clinical instruction and practical ward and dispensary work became more prominent and occupied more than half of the time spent by the student in the classroom. ${ }^{3}$ Clinical experience was obtained mainly in the Philippine General Hospital. Internship, which replaced the 5th year, was made a prerequisite for graduation in 1923.

The 1930's were marked by the acquisition of more modern laboratory facilities, observance of ideal studentfaculty ratios, selective student admission, the holding of clinico-pathologic conferences, and increasing bedside instruction that paralleled the increase in the patient capacity of the Philippine General Hospital.4 On June 1, 1941, the UPCM was formally accredited as a regular member of the Association of American Medical Colleges (AAMC) after a three-month survey of its educational facilities. It became an affiliate member of the AAMC after the granting of independence to the Republic of the Philippines on July 4, 1946 and was re-registered in the Department of Education of the State of New York on September 1, 1948. Perhaps as a result of this recognition, UPCM graduates were the most sought after of all foreign medical graduates by American hospitals at that time. ${ }^{2}$ However, the efflux of our graduates to the United States contributed to the brain drain in the Philippines.

\section{UPCM Curricular Revisions: Community Orientation and Integration}

The first revision of the medical curriculum was undertaken in 1953 by a committee appointed by then Dean Agerico B. M. Sison. A four-year baccalaureate degree became a requirement for admission. After the First National Conference on Medical Education in 1968, the medical curriculum was shortened to four years and the M.D. degree was awarded after clinical clerkship (4th year). An extra year of internship however remained a prerequisite for taking the medical licensure examination. The first communityoriented medical curriculum was described during the 3rd International Conference on Medical Education held in New Delhi, India in 1966. In 1969, the Comprehensive Community Health Program (CCHP) was launched in the
UPCM. The CCHP was a pioneering attempt by the academe to address community health needs through more appropriate community health technologies. It was spearheaded by Dr. Paulo Campos, then chairman of the Department of Medicine, and established in collaboration with the Philippine Department of Health funded by the Rockefeller Foundation. Medical students were required to rotate in CCHP sites during their clinical clerkship and internship years under the supervision of CCHP faculty. ${ }^{4,5}$ Although the CCHP was eventually phased out in the 1980's, the UP Manila has developed instead a Community Health Development Program (CHDP) that allows for interprofessional collaboration in community sites by students from different colleges of UP Manila.

The Association of Philippine Medical Colleges Foundation Inc. (APMCFI), the umbrella organization of all medical schools in the Philippines, was founded in 1967 with seven existing medical schools (including the UP College of Medicine) at that time and the UP Institute of Public Health with the goal of ensuring quality medical education. Among its activities were voluntary accreditation of medical schools, the formulation of core courses in the different disciplines and the formulation of policies and standards for medical education in the country which were adopted by the Board of Medicine of the Professional Regulation Commission. ${ }^{6}$ The World Federation of Medical Education (WFME), recognized as the global body representing medical education worldwide, was founded in Denmark in 1972. The APMCFI was an associate member. Currently, the APMCFI is affiliated with the Association of Medical Education in the Western Pacific Region (AMEWPR), a component of the WFME. The 1970's saw the birth of the integrated curriculum at the Case Western Reserve University in the USA and problem-based learning as an educational strategy in McMaster in Canada and Maastricht in the Netherlands. It was during this time that the UPCM curriculum also underwent several reappraisals and subsequent revisions.

\section{Community orientation}

The establishment of a residency training program in Family Medicine in 1975 paved the way for the introduction of Family and Community Health courses in the medical curriculum. Beginning 1975, Family and Community Health courses were incorporated into the medical curriculum and served as springboards for discussing social issues related to health. These paved the way for the incorporation of community orientation into the UPCM's mission and vision, the development of community-oriented departmental courses, and the establishment of a separate Community Oriented Medical Education (COME) Unit. ${ }^{5}$ Community orientation would later on be incorporated into the UPCM medical curriculum as an outcome expected of its medical graduates. 
In 1979, the UPCM became a founding member of the Network of Community-Oriented Educational Institutions for the Health Sciences, now renamed as The Network Towards Unity for Health (TUFH). ${ }^{1}$ To date, UPCM faculty and students continue to participate in their annual conventions by presenting award-winning projects and researches done in and for the community. In 1982, the primary health care approach was introduced in the curriculum. Dean Alberto Romualdez pushed for the enrichment of the UPCM curriculum with social values and emphasized the primary health care approach in 1984. In 1991, during the term of Dean Alfredo Ramirez, the mission statement of the UPCM was re-written to incorporate community orientation and the primary health care approach. The UPCM mission-vision statement reads: "Towards Leadership and Excellence in CommunityOriented Medical Education Directed to the Underserved."

By 1993, the UPCM College Council resolved that all academic departments should be community-oriented. It was only in 1994 that the APMCFI pushed for the reformation of Philippine medical education, advocating for an innovative, community-oriented curriculum across the country. ${ }^{1}$ The Community Oriented Medical Education (COME) Task Force was first organized under the term of Dean Amelia Fernandez in 1996 and was converted to a COME Unit in 1998. The COME Unit was initially tasked to conduct workshops for faculty to improve their skills in processing students' experiences in the community and incorporate community-oriented teaching-learning strategies in their courses. Community exposure visits were initiated early in the medical curriculum in 1999. The first assignment given to a medical student as he enters the UPCM is to visit his/her local health center and consult as a patient, or accompany a patient, to observe the encounter and to get an idea of the health care system in the local government unit. The experience is then shared and discussed in class. Dean Fernandez also established the Bioethics Committee that was tasked to incorporate the teaching of bioethics in the medical curriculum.

The first innovative step-ladder community-based and competency-based health professional development program was developed by UPCM faculty and approved by the University of the Philippines Board of Regents in April 1976, long before the APMCFI advocated for an innovative, community-oriented curriculum. Dean Alberto Romualdez spearheaded the establishment of the School for Health Sciences (SHS) in Palo, Leyte to answer the need for health professionals (midwives, nurses and physicians) in farflung areas. Students admitted into this program are endorsed and supported by their communities, are required to do community service work periodically and have to return to serve as health practitioners in their home towns. To date, the program boasts that over $90 \%$ of its medical graduates are still in the country, serving in depressed and remote rural communities as municipal health officers, medical officers in district and provincial hospitals, or community practitioners. Siega-Sur states that, "In its early years, the output of its research and development project in Carigara, Leyte, which was jointly carried out with the DOH and the WHO, significantly influenced the restructuring of the country's health care delivery system. It also provided the principal field experience for the formulation of the Health for All policy and the primary health care policy of the country and the WHO Western Pacific Region." 7 The University of the Philippines Manila has since duplicated this program in Baler, Aurora and Koronadal, South Cotabato. This program has also served as a model of many communityoriented programs abroad. ${ }^{1}$

\section{Integration}

The Integrated Liberal Arts and Medicine (INTARMED) program was developed in the 1970's to shorten medical education to seven years. It admits forty deserving high school graduates (called direct entrants) per year into a seven-year program consisting of two years of preparatory medicine and general education subjects (Learning Units I and II), four years of medicine proper (Learning Units III, IV, $\mathrm{V}$ and VI) and one year of internship (Learning Unit VII). It attempts to integrate basic and clinical disciplines. Aside from traditional medicine courses, the program incorporates values education, humanities, history of medicine, health systems management, human rights, bioethics, traditionalalternative-and-complementary medicine, and pedagogy as part of its Art of Medicine courses. When direct entrants reach Learning Unit III, they are joined by one hundred twenty students (lateral entrants) who have completed a baccalaureate degree. This program requires two years of basic sciences taught in an integrated fashion using organ systems as foci for learning, two years of an integrated clinical clerkship and one year of internship as a prerequisite for graduation from the UPCM. The INTARMED program was approved by the UP Board of Regents on April 26, 1982 during the deanship of Dean Gloria T. Aragon, and admitted its first set of students in the same year. Because internship became a prerequisite to graduation, there were no UPCM commencement exercises in 1988 since the first batch of INTARMED students graduated after internship in 1989. The development of this program actually antedated the call for reform of medical education during the World Conference on Medical Education held in Edinburgh in 1988.

In 1992, the Robert Wood Johnson Foundation Commission on Medical Education published their report on educational reforms. Key recommendations which were based on a review of medical schools with successful education reforms included the following:

- "Schools of medicine must ensure that their educational programs integrate the sciences of medical practice through the entire course of study 
- In addition to biological knowledge, physicians must have an understanding of the behavioral and social aspects of health and disease

- Medical schools must expand the context of training beyond tertiary-care hospitals to include, for example, ambulatory care settings, community hospitals, nursing homes and hospices

- In order to exercise their responsibility to assess progress of students, medical school faculty must incorporate effective assessment procedures and techniques that are compatible with their educational goals, and

- To implement the recommendations states above, every school must have an appropriate organizational authority whose leadership is respected and representative of the high level of faculty scholarship." 8

These features have been incorporated into the organ system integrated curriculum that was developed in the UPCM at that time.

Internal and external evaluations of the INTARMED program in 1994 however revealed that there was a need to strengthen the implementation of the integrated curriculum as it still remained heavily discipline-based and teachercentered. In 1997, a Subcommittee on Organ System Integration (SOSI) was convened by then Dean Ramon Arcadio to develop a truly integrated medical curriculum in keeping with the spirit and provisions of the INTARMED program as envisioned by its developers. Former Dean Marita V.T. Reyes was tasked to head this subcommittee. SOSI workshops included student representatives during its deliberations. Eventually, organ systems were chosen as foci for learning. Problem-based learning as a methodology was introduced to the faculty through faculty development workshops conducted by members of the Medical Education Unit (MEU). However, the college opted against using it as the sole educational strategy but encouraged faculty to conduct problem-oriented small group discussions and casebased methods in their courses instead. Walls between departments had to be torn down figuratively as the new curriculum required closer interdepartmental collaboration. Courses in the basic science years were horizontally integrated and grouped by organ systems (OS) and courses were labeled as OS courses. Vertical integration was also observed by introducing clinical experiences early in the medical curriculum. Interviewing skills, traditionally introduced in the second year of medicine, are now learned in Learning Unit III. Ambulatory care rotations in the Out Patient Department constitute twenty-eight weeks of the Learning Unit $\mathrm{V}$ year to emphasize that in clinical practice, more patients are seen in the Out Patient Department rather than in the hospital. Various sites serve as venues for learning such as urban community centers, schools and rural communities. A biopsychosocial approach to the study of health and disease is utilized. The Art of Medicine course was developed to include values, gender sensitivity, pedagogy, bioethics, legal medicine, medical jurisprudence, and complementary and alternative medicine. While preparing for an organ system integrated curriculum, parallel workshops on community orientation were also held at this time facilitated by members of the COME Unit. Faculty had to incorporate COME activities into each course and each learning unit. Two courses on Management are offered in Learning Unit V. The curriculum also deliberately allowed an increase in the number of elective offerings starting from Learning Unit IV to VII. Three tracks for internship were also developed: regular rotating internship (Track A), core internship with electives (Track B) and straight internship (Track C). Some of the additional features of this curriculum include: (1) the addition of learning objectives that develop psychomotor skills and attitudes, (2) focus on the must know, (3) competency-based and outcome-based curricular design, (4) increase in the use of small group discussions vs. lectures, (5) clinical teaching that is complaint-based rather than disease-based, and community-oriented rather than hospital-based, and (6) use of student assessments that are more integrated, emphasize critical thinking and problemsolving, and are criterion-referenced rather than normreferenced. The faculty learned to construct concept maps, learning objectives and instructional designs, and implement innovative teaching-learning strategies and assessment methods during numerous faculty development workshops which were later packaged together as an Integrated Faculty Development Program (IFDP) approved by the College Council on April 4, 2006. Completion of the IFDP remains a pre-requisite to tenure.

On April 21, 2003, the UP-Manila University Council approved the full implementation of the OSI curriculum which was implemented in the following academic year 2004-2005 starting with Learning Unit III, at a time when other medical schools who had tried problem-based learning as a strategy were reverting back to a traditional or a hybrid curriculum. The first batch of graduates under the OSI curriculum graduated in 2009. Graduates of this program have shown comparable, if not better, performance in the physician licensure examinations given by the Professional Regulation Commission as compared to graduates of the traditional medical curriculum. Their interests have also diversified. While the clinician track was most often the only choice after graduation from the traditional curriculum, the OSI curriculum has produced graduates who now go into health policy, research, academe and community practice. A mentoring program was also instituted together with the implementation of the OSI curriculum. The program assigns two UPCM faculty or alumni members to a group of nine to ten students at entry to Learning Unit III. They meet informally on a regular basis three to five times a year to discuss student issues and career plans. Whether this has had a bearing on student outcomes is unclear as the program still needs to be evaluated. 
The UPCM has been granted Level IV Re-Accredited status for its Basic Medical Education program effective April 24, 2015 to November 2019 by the Federation of Accrediting Agencies of the Philippines following a reaccreditation visit by the Philippine Accrediting Association of Schools, Colleges and Universities (PAASCU). The UPCM has also been recognized as a CHED Center of Excellence for Medicine effective December 2015 based on CHED Memorandum Order No. 38, Series of 2015.

\section{Challenges of Curricular Change}

Change is never easy. In spite of numerous workshops with faculty over more than five years to prepare for the OSI curriculum, it is difficult to get a $100 \%$ buy-in. Cooperation and collaboration are essential to ensure the success of any program change. Parents and students have to be oriented to the curriculum at the start of the school year. It is heartening to get feedback from parent doctors who had been trained with a traditional curriculum that they support the OSI curriculum. It is equally disheartening however to listen to students complain about faculty who openly express their distrust and misgivings over the new curriculum and spend the first half of their lectures ranting their complaints. I remember a student who wrote a two-page essay at the back of his questionnaire after an exam, giving mostly negative feedback on the implementation of the curriculum. Learning Unit Academic Committees consisting of all course coordinators of the learning unit and headed by specific department chairmen would meet at least once a month, or more often if necessary, to discuss complaints and provide solutions. Because the courses were taught in a modular fashion, we had to contend with sudden suspensions of classes for bad weather by providing self-instructional modules. Some departments developed textbooks or modules which are still being used today.

One day in 2005, the Dean's office received an unsigned letter addressed To the Gods of Olympus: A Prayer for Relief. The supplication summarized the medical students' confused emotions about the implementation of the OSI curriculum and appealed to the powers that be to put order into what they perceived as disorder and chaos in its implementation. Much of the frustration stemmed from comments made by faculty who were resistant to adapt to change. We had to appease both students and faculty. The letter was discussed in a College Council meeting and Dean Cecilia Tomas appealed to the faculty to support the curricular change and to refrain from airing their grievances during class time. Five years later, I met Dr. Carl Abelardo Antonio, a UPCM 2009 graduate, during one of my community integration sessions for Learning Unit V students. He was working as a physician in the Pasay City Health Office. He promised to send me a sequel to To the Gods of Olympus: A Prayer for Relief. He entitled it To the Gods of Olympus...Revisited. It was a two-page essay. This is an excerpt from his essay:
"Given the benefit of hindsight, I can say this much of OSI: The curriculum gives to the student the gift of seeing the bigger picture of a whole person by integrating subjects within and across levels; it promotes independent learning through protected study time generously allotted per week, the benefit of having electives as early as second year, and the option of pursuing a directed internship track; it fosters critical thinking by exposing students early on to the experience of scientific dialogue in the form of small group discussions and oral case presentations; and (perhaps biased by my field of interest), it has influenced more students to pursue careers locally (about $40 \%$ of the class applied for residency in the Philippine General Hospital alone) and outside the traditional bounds of medical practice (as health officers in the various local government units, and as technical assistants in the Department of Health and World Health Organization).....The curriculum also challenges the stereotype of the physician as merely a clinician, and broadens the students' horizon, allowing him to choose one or more rolels in the Five Star Physician modelthat of an advocate, social mobilizer, manager and researcher." 9

It appears that one of the most important parameters for successful innovations is the support of leadership. The UPCM story is testament to that. Each of the UPCM deans contributed to curriculum development, adding features to the current OSI and community-oriented medical curriculum and steering the college to pursue its mission and vision.

\section{Future Directions}

Curriculum development and improvement is a continuous process. In recent years, outcome-based education has become the by-word for medical education. CHED Memorandum Order No. 18 Series of 2016 mandates the shift to competency-based/outcome-based education for the Doctor of Medicine program. The UPCM has identified eleven learning outcomes for the medical curriculum and has conducted workshops to cascade this to faculty course coordinators for incorporation into each module and course in the OSI curriculum. Evaluation of the curriculum is ongoing and the Curriculum Committee has been tasked to prepare for certification by the ASEAN University Network by 2018. This is in keeping with efforts towards globalization and ASEAN integration.

\section{Statement of Authorship}

All authors have approved the final version submitted.

Author Disclosure

All authors declared no conflict of interest. 


\section{Funding Source}

This paper was funded by the author.

\section{References}

1. Arcadio RL. Humanity and the U.P. College of Medicine: Third Centennial Lecture. In: Arcellana-Nuqui EY, Danguilan JLJ, Agbayani $\mathrm{BF}$, et al, eds. Siyento: The UP College of Medicine Centennial Commemorative Book. UPCM Centennial Executive Committee; 2005. pp. 210-218.

2. Sison $\mathrm{ABM}$, Rotor $\mathrm{AB}, \mathrm{Campos} \mathrm{PO}$. College of Medicine, University of the Philippines Semi-Centennial 1957. Journal of Medical Education. 1957; 32(10):687-96.

3. Cordero N. A personalized history of the UP College of Medicine. In: Arcellana-Nuqui EY, Danguilan JLJ, Agbayani BF, et al, eds. Siyento: The UP College of Medicine Centennial Commemorative Book. UPCM Centennial Executive Committee; 2005. pp. 35-51.

4. Caballes AB. The UP College of Medicine: A Creation of the Twentieth Century. In: Arcellana-Nuqui EY, Danguilan JLJ, Agbayani BF, et al, eds. Siyento: The UP College of Medicine Centennial Commemorative Book. UPCM Centennial Executive Committee; 2005. pp. 18-34.
5. Fernandez-Marcelo PH. Striving for Relevance: Community Oriented Medical Education in the University of the Philippines. In: FernandezMarcelo PH, Salonga RM, eds. Community Oriented Medical Education in the University of the Philippines. The Community Oriented Medical Education Unit, College of Medicine, University of the Philippines Manila, Manila, Philippines; 2010. pp. 7-32.

6. Association of Philippine Medical Colleges Foundation Inc. [Online] Available from http://webv2.apmcf-ph.net/apmc_wp/about-apmc/ vision-and-mission

7. Siega-Sur JLJ. The UPM-SHS: Where the Health Workers are Trained to Stay and Serve. In: Arcellana-Nuqui EY, Danguilan JLJ, Agbayani BF, et al, eds. Siyento: The UP College of Medicine Centennial Commemorative Book. UPCM Centennial Executive Committee; 2005. pp. 322-325.

8. Robert Wood Johnson Foundation Establishes Commission on Medical Education to Assess Medical School Curriculum and Recommend Changes: Planning for a study commission on the science basic to medicine [Online]. Available from https://www.rwjf.org/content/dam/ farm/reports/program_results_reports/2002/rwjf14092.

9. Antonio CAT. To the Gods of Olympus...Revisited. 2010. Unpublished.

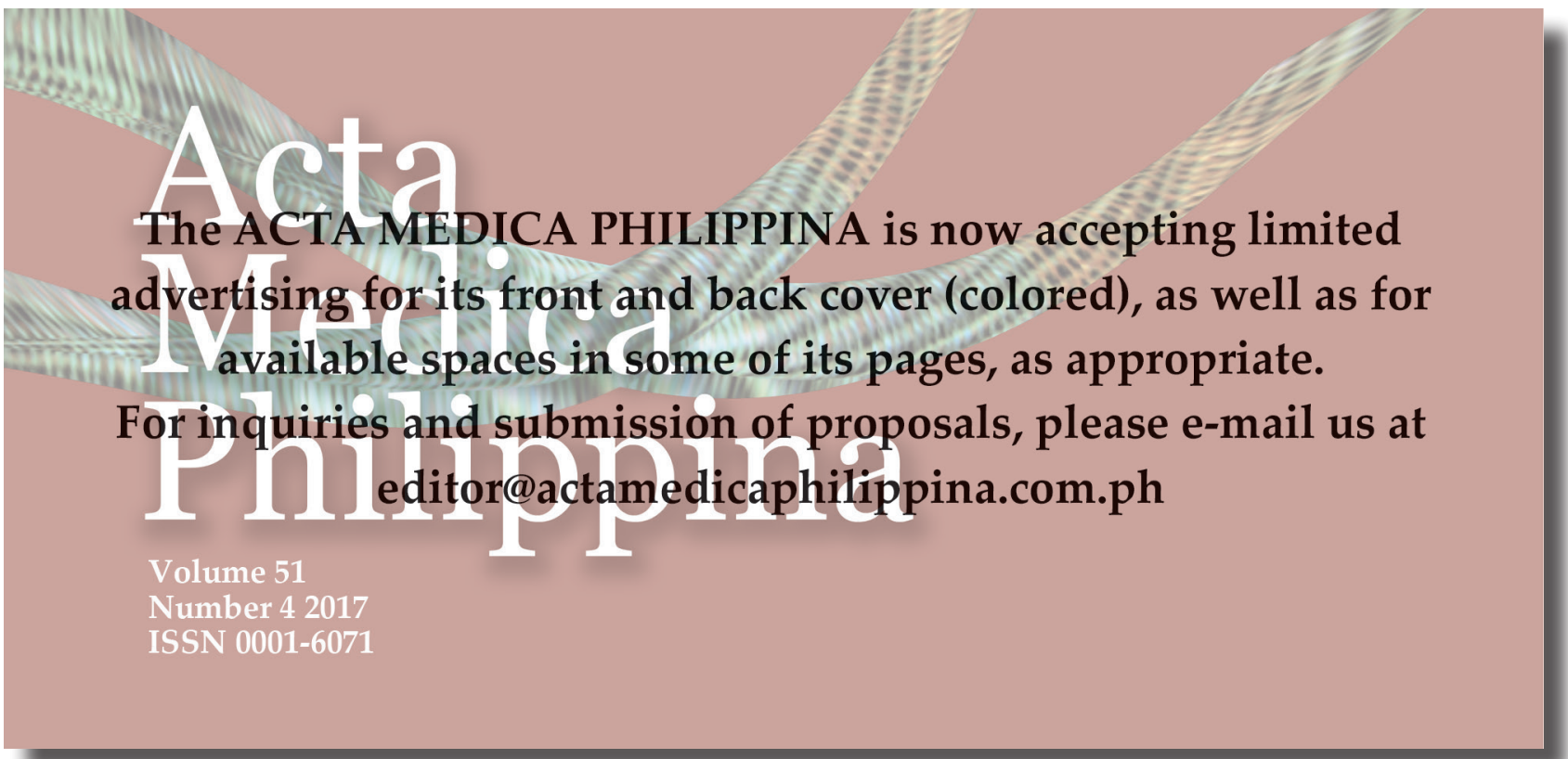

